\title{
Personalized Health and the Coronavirus Vaccines -Do Individual Genetics Matter?
}

\author{
Bianca N Valdés-Fernández ${ }^{1,2}$, Jorge Duconge ${ }^{3}$, Ana M Espino ${ }^{1}$, and Gualberto Ruaño ${ }^{4}$ \\ ${ }^{1}$ Department of Microbiology, School of Medicine, University of Puerto Rico-Medical \\ Sciences \\ ${ }^{2}$ Department of Biology, University of Puerto \\ ${ }^{3}$ Department of Pharmaceutical Sciences, School of Pharmacy, University of Puerto Rico \\ ${ }^{4}$ Institute of Living at Hartford Hospital
}

May 20, 2021

\begin{abstract}
This article assesses the role of recipient genetics to COVID-19 vaccine responses. Vaccines represent preventative interventions suitable to an immunogenetic perspective to predict how human variability will influence their safety and efficacy. The genetic polymorphism among individuals within any population can make possible that the immunity elicited by a vaccine is variable in length and strength. The same immune challenge (either virus or vaccine) could provoke partial, complete or even failed protection for some individuals treated under the same conditions. We review genetic variants and mechanistic relationships among chemokines, chemokine receptors, interleukins, interferons, interferon receptors, toll-like receptors, histocompatibility antigens, various immunoglobulins and major histocompatibility complex antigens. These are the targets for variation among macrophages, dendritic cells, Natural Killer cells, T- and B- lymphocytes, and complement. The acute nature of vaccine reactogenicity is reminiscent of the time course of adverse drug reaction mediated by the immune system. The variety of technology platforms (mRNA, viral vectors) utilized currently to produce vaccines against SARS-CoV-2 infections may each also trigger genetically distinct immune reactogenic profiles. With biobanking of recipient genomic DNA and serum immunoprofiling, global COVID-19 vaccinations could launch a new era of research and clinical translation in personalized health.
\end{abstract}

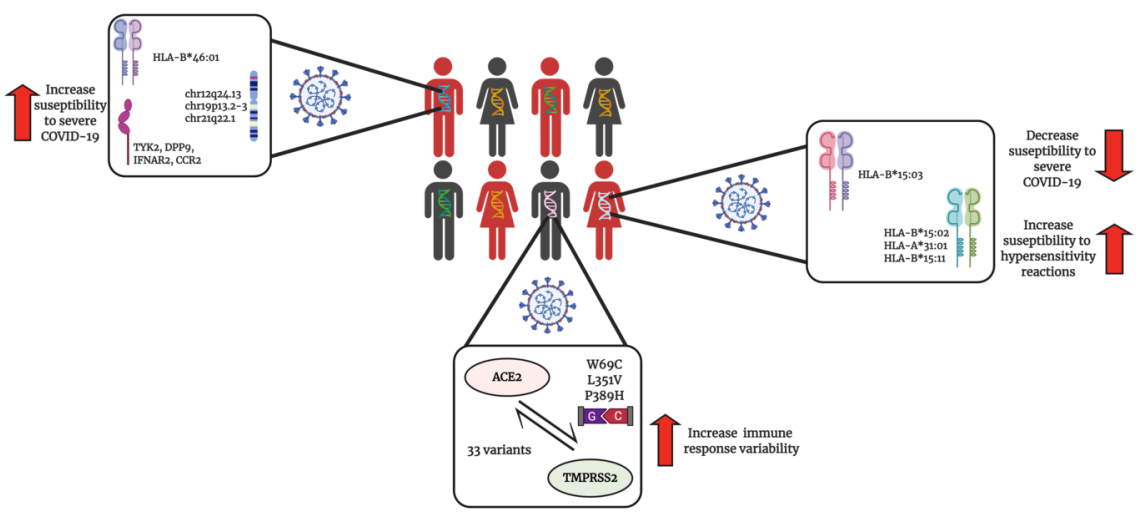

\section{Hosted file}


COVID19 Vaccine Genetics Authorea.pdf available at https://authorea.com/users/414269/ articles/522352-personalized-health-and-the-coronavirus-vaccines-do-individual-geneticsmatter 